\title{
Rapid detection of genetic variability in chrysanthemum (Dendranthema grandiflora Tzvelev) using random primers
}

\author{
KIRSTEN WOLFF* $\uparrow \&$ JENNY PETERS-VAN RIJN $\dagger$ \\ *University of Leiden, PO Box 9516, 2300 RA Leiden; and †TNO Nutrition and Food Research, PO Box 360,3700 AJ \\ Zeist, The Netherlands
}

\begin{abstract}
Genetic variation in chrysanthemum (Dendranthema grandiflora) was studied using a recently developed technique generating Random Amplified Polymorphic DNAs (RAPDs). It appeared that variation between cultivars was high and that the cultivars used could be distinguished from each other by using only two different primers. A family of cultivars, derived from one original cultivar by vegetative propagation, had identical fragment patterns. Because of the high level of polymorphism and clonal stability RAPD fragments are useful for cultivar identification. Genetic variability among related Dendranthema species was too high to study genetic distances either among cultivars within chrysanthemum or among species related to chrysanthemum.
\end{abstract}

Keywords: chrysanthemum, cultivar identification, genetic variability, PCR, RAPDs.

\section{Introduction}

Dendranthema grandiflora Tzvelev (Chrysanthemum morifolium Ramat.) is a polyploid belonging to a hexaploid species complex comprising six or seven species (Dowrick, 1953). On average 54 chromosomes are present, although counts from 36 to 75 are possible (Langton, 1989). Regular bivalents are formed during meiosis suggesting an allopolyploid origin (Dowrick, 1953; Watanabe, 1977). It is not known whether most characters are inherited in a disomic or a hexasomic way. Bivalent formation suggests a disomic transmission. Presence of carotenoid pigmentation, however, appeared to be transmitted in a hexasomic way (Langton, 1989). Chrysanthemum has a strong selfincompatibility system, thus causing many crosses between related or unrelated individuals to be unsuccessful. Usually only between 5 and 50 per cent of crosses between sibs in an $F_{1}$ are compatible (Drewlow et al., 1973; Ronald \& Ascher, 1975; Zagorski et al., 1983; Stephens et al., 1984). The genetics of the sporophytic self-incompatibility system is not completely resolved but probably several loci are involved (more than two) and there is dominance of alleles (Zagorski et al., 1983; Stephens et al., 1984). Polyploidy, unknown

Correspondence: K. Wolff, TNO, PO Box 360, 3700 AJ Zeist, The Netherlands. origin of the species and the self-incompatibility system caused many genetic analyses to be unsuccessful in chrysanthemum and, therefore, little is known about the genetics of the species.

Commercially chrysanthemum is mainly asexually propagated by terminal, vegetative cuttings (Dowrick \& El-Bayoumi, 1966; Teynor et al., 1989). Propagation via seeds is usually used only to develop new cultivars since biparental crosses give an extremely variable $F_{1}$ differing in many morphological characters (Dowrick \& El-Bayoumi, 1966).

In this study we examine genetic variability in the species Dendranthema grandiflora and among related species. We expect the variability among cultivars within chrysanthemum to be large considering the outcrossing nature of the mating system (Brown, 1979; Loveless \& Hamrick, 1984; Wolff, 1991). We further expect that many loci are in a heterozygous state and these loci may, therefore, show segregation in the offspring of a biparental cross. Our future goal is to use molecular markers for cultivar identification and in mapping studies. The present study is the first one exploring molecular variability in chrysanthemum.

During recent decades several techniques have been introduced that detect molecular variability within and among several species. Three of these widely applied techniques are the use of restriction fragment length polymorphisms (RFLPs) (e.g. Helentjaris et al., 1986), 
DNA fingerprinting (Jeffreys et al., 1985) and specific amplification of polymorphic DNA fragments with PCR (Weining \& Langridge, 1991). Prior knowledge of the DNA composition of the species and/or the presence of useful probes is, however, required. Recently a new and rapid technique to detect polymorphisms was developed using the polymerase chain reaction (PCR) and random primers to amplify DNA (Welsh \& McClelland, 1990; Williams et al., 1990). The technique is named RAPD after Random Amplified Polymorphic DNAs (Williams et al., 1990). The DNA fragment patterns generated can discriminate between individuals, cultivars or species (Arnold et al., 1991; Caetano-Anolles et al., 1991; Hu \& Quiros, 1991; Quiros et al., 1991; Hadrys et al., 1992). In some cases the transmission of polymorphic fragments and the localization of the amplified DNA fragment on the genome was determined (Williams et al., 1990; Martin et al., 1991). RAPDs have already been used successfully in mapping studies in Arabidopsis (Reiter et al., 1992) and in tomato (Aarts et al., 1991; Martin et al., 1991; Klein-Lankhorst et al., 1991). Michelmore et al. (1991) showed that the RAPD markers are extremely useful in a bulked segregant analysis to detect diseaseresistance genes in lettuce.

The newly developed technique of RAPD seems suitable for studying genetic variability in chrysanthemum and related species as species-specific probes for studying RFLPs are not present at this moment. In a preliminary study we observed that the polymorphic RAPD markers have a genetic basis: all fragments present in the offspring of a biparental cross were clearly transmitted from parents to offspring (Wolff, unpublished results). Only one non-parental band was seen in one of the offspring out of 43 polymorphic fragments scored using nine primers. Variability within Dendranthema grandiflora will be studied by looking at genetic variability among cultivars, and at the same time determine whether RAPDs are useful for identifying cultivars. Furthermore, we can test the stability of fragment patterns in mutant members of a clonal family of cultivars that differ in specific morphological and physiological characters. Genetic variability among related chrysanthemum species will be analysed by studying several species from this polyploid species complex.

\section{Materials and methods}

\section{Plant material and experimental setup}

The plant material was kindly provided by three Dutch chrysanthemum breeding companies as leaf material, freshly cut from adult plants. In chrysanthemum breeding it is often the case that from a successful cultivar other cultivars are obtained by (somatic) mutation with, amongst others, different flower colour. These new cultivars are made by irradiating the successful original cultivar with gamma-rays or by cloning the original cultivar into thousands of clonal derivatives and looking for a spontaneous somatic mutation. In this study we used one specific family, the family derived from $\mathrm{CH} 36$. The original cultivar is pink flowered and by now at least 14 different coloured cultivars have been obtained by spontaneous mutation and four derived by irradiation. To study clonal stability 13 members of this family and 27 primers (numbers 1 to 26 and 29) were used.

For cultivar variability 18 different cultivars from three breeders and eight primers (numbers 1, 13, 14, $15,18,21,22$ and 23) were used. Designation of the cultivars used and their origin is given with Fig. 1.

Variability among species was studied using six primers (numbers 3, 4, 15, 21, 22 and 23) and 15 individuals, representing 13 different species. Names of the species and their ploidy level, as far as information is available from the literature, are given with Fig. 3.

\section{DNA extraction}

Chrysanthemum leaves were ground in liquid nitrogen and freeze dried under vacuum. The dry powder was kept at $-20^{\circ} \mathrm{C}$. DNA was extracted from the dry powder according to Saghai-Maroof et al. (1984) with the modifications of a double chloroform/isoamylalcohol (24:1) treatment, the use of cold absolute ethanol to precipitate the DNA, two washes in 76 per cent ethanol $/ 0.2 \mathrm{~m} \mathrm{NaAc}$ prior to the wash in 76 per cent ethanol/10 $\mathrm{mm} \mathrm{NH}_{4} \mathrm{OAc}$ and the dissolving of the DNA in $10 \mathrm{~mm}$ Tris $/ 1 \mathrm{~mm}$ EDTA $(p \mathrm{H} 8.0)$. Yields were usually $70 \mu \mathrm{g}$ DNA per $300 \mathrm{mg}$ of powder per extraction.

\section{Primer synthesis}

Oligodeoxynucleotide primers were synthesized using a DNA synthesizer 381A from Applied Biosystems. After deprotection of the oligos, two extractions with phenol/chloroform $(1: 1)$ and two extractions with chloroform were done. The primers were numbered according to the order of synthesis (Table 1 ); numbers one to eleven are identical to the primers published by Williams et al. (1990).

\section{Amplification reaction conditions}

The use of RAPDs was developed by Williams et al. (1990). The DNA was amplified under conditions similar to normal PCR, with the exception that only a 
Table 1 Nucleotide sequences of the primers used for generating RAPDs

\begin{aligned} & \hline 1 5'-TGG TCA CTG A-3' \\ & 2 5'-AGG TCA CTG A-3' \\ & 3 5'-TCG TCA CTG A-3' \\ & 4 5'-TGC TCA CTG A-3' \\ & 5 5'-TGG ACA CTG A-3' \\ & 6 5'-TGG TGA CTG A-3' \\ & 7 5'-TGG TCT CTG A-3' \\ & 8 5'-TGG TCA GTG A-3' \\ & 9 5'-TGG TCA CAG A-3' \\ & 10 5'-TGG TCA CTC A-3' \\ & 11 5'-TGG TCA CTG T-3' \\ & 12 5'-CGG TCA CTG T-3' \\ & 13 5'-CGG CCA CTG T-3' \\ & 14 5'-CGG CCC CTG T-3' \\ & 15 5'-CGG CCC CGG T-3' \\ & 16 5'-TGG TGA GTG T-3' \\ & 17 5'-TCA CGA TGC A-3' \\ & 18 5'-GCA AGT AGC T-3' \\ & 19 5'-GGA ATA AGC G-3' \\ & 20 5'-AGG AGA ACG G-3' \\ & 21 5'-GCT CGT CGC T-3' \\ & 22 5'-GCA TGT CGT G-3' \\ & 23 5'-GCC TGT CGA T-3' \\ & 24 5'-GCG TGA CTT G-3' \\ & 25 5'-TGG TCC TGC G-3' \\ & 26 5'-TGC TGG GCG G-3' \\ & 29 5'-GGG CGG GGC G-3' \\ & \hline\end{aligned}

single primer was used and that the nucleotide order of the primer was random, with the only requirement that the $\mathrm{G}+\mathrm{C}$ content be at least 50 per cent (Williams et al., 1990). In a previous experiment the reaction conditions were optimized (Wolff et al., 1993). Reactions were performed in a volume of $50 \mu \mathrm{l}$ containing $20 \mathrm{~mm}$ Tris- $\mathrm{HCl}, p \mathrm{H} 8.3,50 \mathrm{~mm} \mathrm{KCl}, 3 \mathrm{~mm} \mathrm{MgCl}_{2}, 0.001$ per cent gelatin, $100 \mu \mathrm{M}$ each of dATP, dCTP, cGTP and dTTP, $0.2 \mu \mathrm{M}$ primer, $25 \mathrm{ng}$ of chrysanthemum genomic DNA, and $1 \mathrm{U}$ of Taq polymerase (Amplitaq, Perkin Elmer Cetus) using a Perkin Elmer 9600 thermal cycler. After 5 min heating at $94^{\circ} \mathrm{C} 45$ cycles were run. Each cycle consisted of $1 \mathrm{~min}$ at $94^{\circ} \mathrm{C}, 1 \mathrm{~min}$ at $36^{\circ} \mathrm{C}$ and 2 min at $72^{\circ} \mathrm{C}$. Ramp time between annealing temperature and $72^{\circ} \mathrm{C}$ was set at $0.3-0.4^{\circ} \mathrm{C} \mathrm{s}^{-1}$ (a total of $2 \mathrm{~min}$ ). A ramp time shorter than $1.5 \mathrm{~min}$ led to low or no DNA amplification. In a preliminary experiment the influence of DNA and polymerase concentration was tested with three primers and two different DNA templates.

Amplified DNA fragments were separated by electrophoresis in a 1.4 per cent agarose gel with a TBE buffer system (Sambrook et al., 1989). The total reaction volume was loaded on the gel. Gels were stained with ethidium bromide and fragment patterns were photographed for further analysis.

\section{Observations}

Different fragments produced with each primer were numbered sequentially and presence or absence of fragments in each individual was scored. Individuals from the same row on one gel were compared with each other. Fragments with a medium or strong signal were taken into account as these fragments are fully reproducible. Fragments with the same mobility on the gel but with different intensities were not distinguished from each other when cultivars or species were compared with each other.

\section{Variability}

Variability among cultivars and among species was expressed as the similarity $S$. This is calculated as:

$S=\frac{2 \times N_{\mathrm{AB}}}{N_{\mathrm{A}}+N_{\mathrm{B}}}$,

in which $N_{\mathrm{AB}}$ is the number of bands shared by individuals $\mathrm{A}$ and $\mathrm{B}$, and $N_{\mathrm{A}}$ and $N_{\mathrm{B}}$ are the number of bands in individuals $\mathrm{A}$ and $\mathrm{B}$, respectively. The similarity measure can also be called band sharing. Distance can be calculated as $D=1-S$ (Swofford \& Olsen, 1990). The chance of finding two individuals with the same fragment pattern can be calculated as the mean similarity $(\bar{S})$ to the power of the mean number of bands $(\bar{N})$ (Nybom \& Hall, 1991).

\section{Results}

The Dutch cultivars showed strongly differing fragment patterns (Fig. 1). On average, band sharing was 0.66 (range $0.49-0.77$ ). Only a few primers (1-3), depending on the number of polymorphic fragments generated by the primers chosen, were needed to distinguish all cultivars in this study. Each primer gave on average seven bands per individual. This, together with a mean similarity of 0.66 , gives a chance of finding two identical patterns in two individuals of $5 \times 10^{-2}$ for one primer, $3 \times 10^{-3}$ when using two primers and $1.6 \times 10^{-4}$ when using three primers. Similarity among cultivars was calculated for within breeding company and a between company comparison (only the two largest groups, from Fides and from CBA were compared). Cultivars obtained from CBA were slightly more similar $(t$-test; $P=0.028)$ to each other $(S=0.71)$ than they were to cultivars from Fides $(S=0.66)$. Cultivars from Fides were as similar to each other 


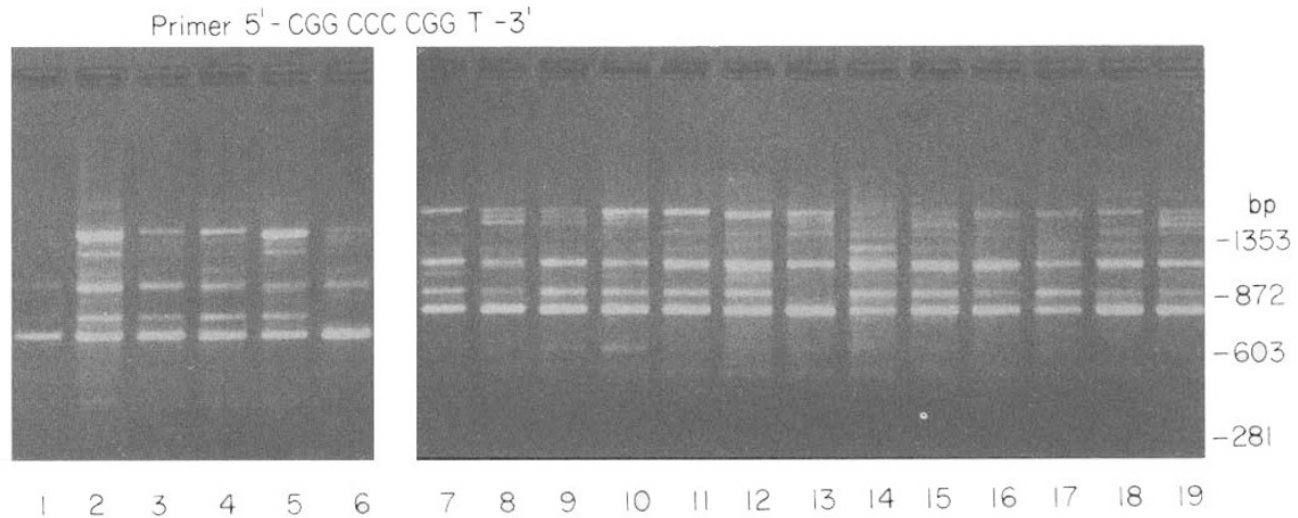

Fig. 1 RAPD fragment pattern of several Dutch chrysanthemum cultivars. From lane 1 to lane 18 cultivars with the following numbers are used: $\mathrm{CH} 1, \mathrm{CH} 2, \mathrm{CH} 3, \mathrm{CH} 4, \mathrm{CH} 5, \mathrm{CH} 6, \mathrm{CH} 7, \mathrm{CH} 8, \mathrm{CH} 9, \mathrm{CH} 10$ (all from Fides), $\mathrm{CH} 11, \mathrm{CH} 12, \mathrm{CH} 14, \mathrm{CH} 17$ (from CBA), CH53, CH54 (from Fides), CH55, CH57 (from Hoek Breeding).

Primer $5^{\prime}-$ TCG TCA CTG A-3'

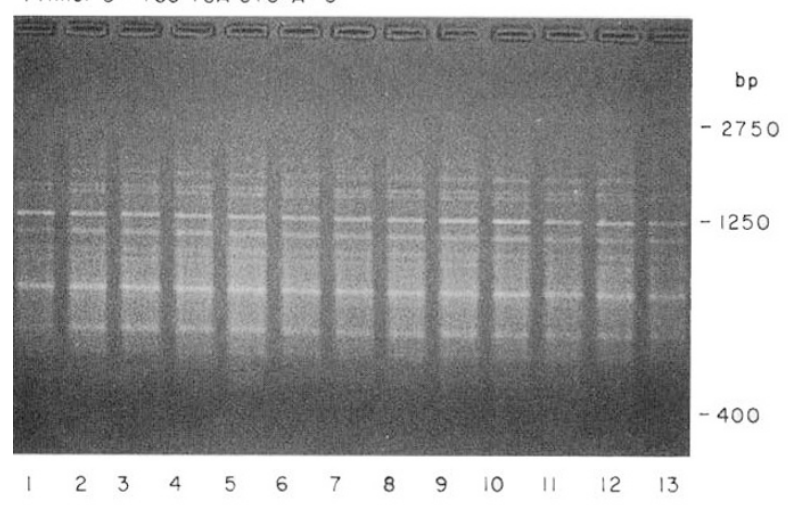

Fig. 2 RAPD fragment of a family of cultivars derived from number $\mathrm{CH} 36$.

$(S=0.66)$ as to cultivars from $\mathrm{CBA}(S=0.66)$. The cultivars belonging to one family, all derived from CH36, were extremely similar (Fig. 2). Only one primer (number 19) out of the 27 tested gave slightly different patterns for these 13 mutant cultivars. In this case there was marginal variation for the fainter bands only.

The different Dendranthema species were studied with six primers. Genetic variability among the species was high (Fig. 3). Some primers yielded extremely different banding patterns in each species; many bands were present in only one of the species. Mean similarity among species was 0.49 (range $0.22-0.77$ ). This is significantly lower than similarity among chrysanthemum cultivars $(P<0.001, t$-test $)$. Two of the species were represented by two individuals from a different origin. In both cases the two individuals of one species were as different from each other as from individuals from other species. Therefore, the high variability within chrysanthemums seems to be present within other related species as well. The ploidy level of some of the species is known from the literature (see Fig. 3 and Kawata, 1978). There was no relationship between the ploidy level and the number of RAPD fragments generated (c.f. Fig. 3: $4 \times$ species in lanes 1 and 5 and $10 \times$ species in lanes 2 and 3 ).

\section{Discussion}

\section{Genetic variability in chrysanthemum}

The chrysanthemum varieties show a high level of genetic variability as was expected from a plant possessing a mating system of strict outcrossing. Apparently the regular introduction of material from Japan and other countries, which is considered a good breeding practice, has resulted in the maintenance of high levels of genetic variability in the gene pool. Levels of variability for RAPD in this species are comparable to some other species studied (Carlson et al., 1991; Hu \& Quiros, 1991; Reiter et al., 1992; Van Heusden \& Bachmann, 1992; Welsh et al., 1991). Some of the wild and agricultural species studied show far lower levels of variability, probably because of their mating system and the breeding strategy (Arnold et al., 1991; Halward et al., 1992).

Cultivar identification and cultivar relatedness are important issues for horticultural breeders. The application of RAPDs seems very valuable in this regard. If primers are chosen that are known to give highly polymorphic banding patterns in chrysanthemum, only a few primers are needed to distinguish cultivars, as long as these cultivars are not mutants of each other. Therefore, cultivars derived vegetatively from one original cultivar cannot be distinguished from each other using 
Fig. 3 RAPD fragment pattern of related Chrysanthemum and Dendrathema species. The species' names and ploidy level, if known, are from lane 1 to $14: 1$. D. yoshinaganthum Makinoi ex Kitamura $(4 \times)(\mathrm{CPRO}) 2$. D. arcticum L. Tzvelev $(10 \times)(8 \times$ Dowrick, 1952) (CPRO) 3. D. pacificum (Nakai) Kitamura $(10 \times)(\mathrm{CPRO}) 4$. D. shiwogiku (Kitamura) Kitamura ( $8 \times$, $10 \times)($ CPRO $) 5 . D$. indicum L. Des Moul $(4 \times, 6 \times)($ CPRO $) 6 . D$. zawadskii (Herb.) Tzvelev $(8 \times$, Krogulevich, 1978)(CPRO) 7. C. nankingense Handel-Mazetti (Sharman) 8. C. zawadskii Herbich ssp. latilobum (maxim.) Kitagawa 'Pink Procession' $(4 \times)(4 \times, 6 \times$ Lee, 1967,1975$)$ (USDA) 9. C. yezoense T. Maek. $(10 \times$, Dowrick, 1952) 10. D. pacificum (Nakai) Kitamura $(10 \times)($ Sharman $) 11$. D. weyrichii (Maxim.) Tzvelev $(8 \times)$ $(6 \times$ Shimotomai, 1932) (CPRO) 12. D. xrubellum Sealy 'Clare Curtis' $(2 \mathrm{n}=63$ Dowrick, 1952) (Sharman) 13. C. wakasaense Shimot. ex Kitamura (4 $\times$, Dowrick, 1952)(CPRO) 14. D. grandiflora Tzvelev. $(6 \times$ Dowrick, 1952). Chromosome counts are from Kawata (1978), except if noted otherwise.
Primer $5^{\prime}-\operatorname{CGG}$ CCC CGG $T-3^{\prime}$

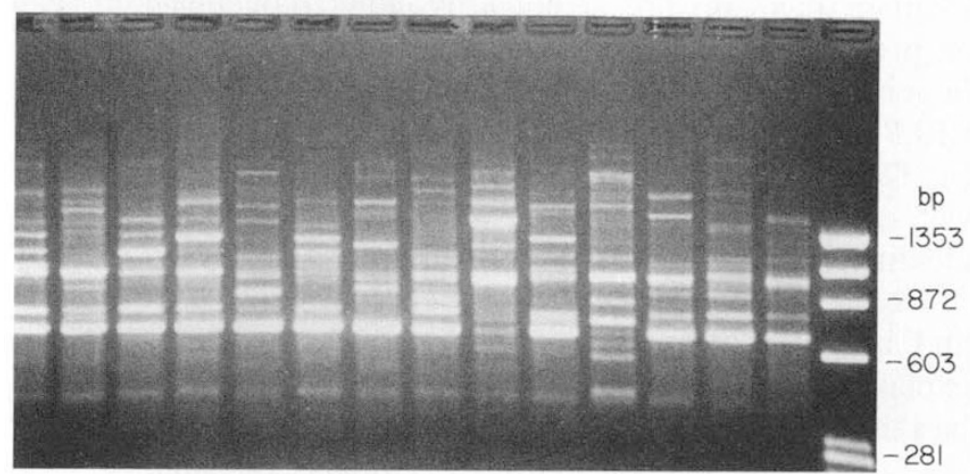

Primer 5'- GCC TGT CGA T-3'

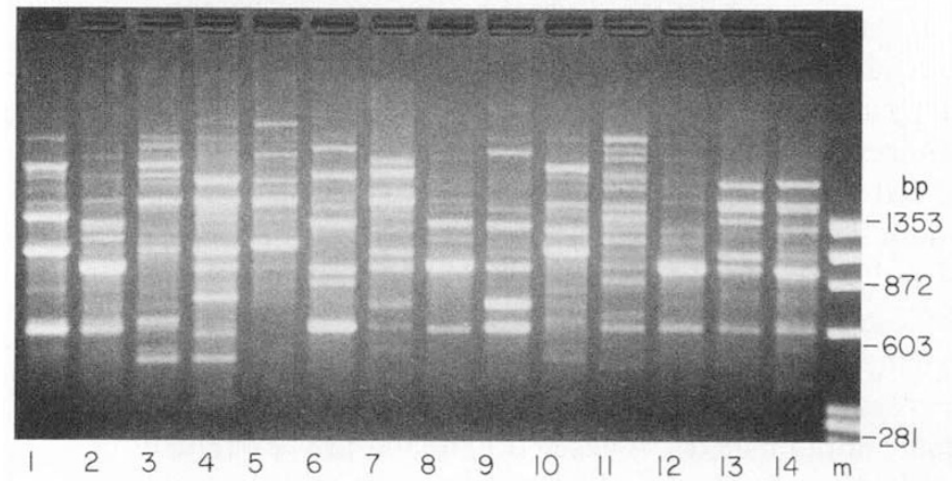

this technique. The members of these families originate from each other by mutations. It is not known whether these are point mutations or inversions, deletions or even loss of chromosomes. Observations by Dowrick \& El-Bayoumi (1966) that morphological mutations often coincide with a difference in chromosome number, seem not to be confirmed by our observation as no differences in RAPD fragment pattern among somaclonal cultivars are observed in this study. The mutations causing the morphological differences may be localized on a small part of the genome.

Similarity (band sharing) can be used as a measure of relatedness (Nybom \& Hall, 1991; Welsh et al., 1991). $\mathrm{Hu}$ \& Quiros (1991) studied genetic variability in Brassica oleracea, and found higher similarities among cultivars from one company than between different company. We found that for one company the cultivars may be slightly more related to each other than to cultivars from another companies. The number of cultivars in this study is, however, too low for definitive conclusions. More cultivars are needed to be conclusive about relatedness within and among these groups.

\section{Genetic diversity among Dendranthema and Chrysanthemum species}

Genetic variation among Dendranthema and Chrysanthemum species, related to the cultivated chrysanthemum, is extremely high, with a very low similarity among species. Besides that, genetic variation within species is also very high. Therefore, RAPDs do not seem useful for determining distances between these species. The usefulness of RAPDs in phylogenetic studies may be different in species that have a low genetic variability within species and where the species are more closely related. In Louisiana irises variation within species was low and natural hybrids among the species were identified because they possessed fragments of both species (Arnold et al., 1991). In Arachis species dendrograms were generated using RAPD fragments as characters (Halward et al., 1992). These dendrograms showed relationships among Arachis species that were in concordance with species relationships derived from allozymes, RFLPs and morphological characters. Although RAPDs may be useful in studying genetic relationships of closely related species the general use of RAPD fragment patterns for taxo- 
nomic purposes is debatable. One should at least check whether fragments are identical by either sequencing or, probably easier, by using the fragments as a probe. In general, other methods, like sequencing or cpDNA RFLP analysis, are preferred in taxonomic studies (see e.g. Dowling et al., 1990). In a forthcoming study we will determine copy number of fragments and test identity to similar fragments from different individuals.

The absence of a correlation between ploidy level and numbers of fragments generated can easily be explained by the fact that PCR reactions are largely based on competition processes among molecules and not solely on the presence or absence of some sequences.

The high levels of variability of RAPD fragments in chrysanthemum renders these RAPD fragments good candidates for cultivar identification and genetic analysis. For specific segregation analyses large numbers of offspring and offspring from several types of crosses are needed; this will be pursued in a subsequent study. The preliminary data on the transmission of polymorphic RAPD fragments seems to point at a diploid-like inheritance; 25 out of 43 polymorphic fragments, present in only one of the parents, segregated in a 1:1 (presence:absence) fashion (Wolff, data unpublished). These fragments are extremely valuable in studies in which markers are used to localize QTL. Furthermore, these polymorphic markers are analogous to single-dose restriction fragments (SDRFs) as described by Wu et al. (1992). They describe how SDRFs are extremely useful in mapping studies in polyploids and how they can be used to distinguish allopolyploidy from autopolyploidy. We have to explore the problems that the hexaploidy of the organism and the dominance of the fragments may cause in future research.

\section{Acknowledgements}

This is publication number 5 of the PBTS-project 'Rapid biotechnological detection of resistance in chrysanthemum against insect pests'. The project is a joint activity of the University of Leiden (Population Biology), TNO-Zeist (Nutrition and Food Research) and the chrysanthemum breeders CBA, Fides Research and Breeding and Hoek Breeding. It is subsidized by Stipt (Ministry of Economic Affairs). Several Dendranthema species were a kind gift of Jan de Jong, CPRO, Wageningen; Joe L. Sharman, Monksilver Nursery, Cottenham, England; and the North Central Regional Plant Introduction Station, USDA-ARS, Ames, Iowa for which we are highly grateful. We thank Robert Campbell, Annelies Hofman, Albert Kamping and Ed van der Meyden and an anonymous reviewer for helpful comments on an earlier version of the manuscript.

\section{References}

AARTS, J. M. M. J. G., HONTELEZ, J. G. J., FISCHER, P., VERKERK, V., VAN KAMMEN, A. AND ZABEL, P. 1991. Acid phosphatase-1, a tightly linked molecular marker for root-knot nematode resistance in tomato: from protein to gene, using PCR and degenerate primers containing deoxyinosine. Plant Mol. Biol., 16, 657-661.

ARNOLD, M. L., BUCKNER, C. M. AND ROBINSON, J. J. 1991. Pollenmediated introgression and hybrid speciation in Louisiana irises. Proc. Natl. Acad. Sci., U.S.A., 88, 1398-1402.

BRown, A. H. D. 1979. Enzyme polymorphism in plant populations. Theor. Pop. Biol., 15, 1-42.

CAETONA-ANOLLES, G., BASSAM, B. J. AND GRESSHOFF, P. M. 1991. DNA amplification fingerprinting using very short arbitrary oligonucleotide primers. Bio. Technology, 9, $553-557$.

CARLSON, J. E., TUlSIERAN, J. K., GLAUbitZ, J. C., LUK, V. W. K., KAUfFELDT, C. AND RUTLEDGE, R. 1991. Segregation of random amplified DNA markers in F1 progeny of conifers. Theor. Appl. Genet., 83, 194-200.

DOWLING, T. E., MORITZ, C. AND PALMER, J. D. 1990 . Nucleic acids II: restriction site analysis. In: Hillis, D. M. and Moritz, C. (eds) Molecular Systematics, Sinauer Ass., pp. 250-317.

DOWRICK, G. J. 1952. The chromosomes of Chrysanthemum, I: the species. Heredity, 6, 365-375.

DOWRICK, G. J. 1953. The chromosomes of Chrysanthemum, II: garden varieties. Heredity, 7, 59-72.

DOWRICK, G. J. AND EL-BAYOUMI, A. 1966. The origin of new forms of the garden Chrysanthemum. Euphytica, 15, $32-38$.

DREWLOW, L. W., ASCHER, P. D. AND WIDMER, R. E. 1973. Genetic studies of self incompatibility in the garden chrysanthemum, Chrysanthemum morifolium Ramat. Theor. Appl. Genet., 43, 1-5.

HADRYS, H., BALICK, M. AND SCHIERWATER, B. 1992. Applications of random amplified polymorphic DNA (RAPD) in molecular ecology. Molec. Ecol., 1, 55-63.

HALWARD, T., STALKER, T., LARUE, E. AND KOCHERT, G. 1992. Use of single-primer DNA amplifications in genetic studies of peanut (Arachis hypogaea L.). Plant Mol. Biol., 18, 315-325.

HELENTJARIS, T., SLOCUM, M., SCHAEFER, A. AND NIENHUIS, J. 1986. Construction of genetic linkage maps in maize and tomato using restriction fragment length polymorphisms. Theor. Appl. Genet., 72, 761-769.

HU, J. AND QUIROS, C. F. 1991. Identification of broccoli and cauliflower cultivars with RAPD Markers. Plant Cell. Rep., 10, 505-511.

JEFFREYS, A. J., WILSON, v. AND THEIN, S. L. 1985. Hypervariable 'minisatellite' regions in human DNA. Nature, 314, $67-73$.

KAWATA, J. 1978. Japanese cultivars and wild species; their useful characteristics for chrysanthemum breeding. In: 
Langton, F. A. (ed.) Eucarpia Meeting on Ornamentals, Littlehampton, UK, pp. 33-48.

KLEIN-LANKHORST, R. M., VERMUNT, A., WEIDE, R., LIHARSKA, T. AND ZABEL, P. 1991. Isolation of molecular markers for tomato (L. esculentum) using random amplified polymorphic DNA (RAPD). Theor. Appl. Genet., 83, 108-114.

KRogulevich. 1978. In: Malyshev, L. I. and Peshlcova, G. A. (eds) Flora of the Prebaikal, Novosibirsk, pp. 19-48.

LANGTON, F. A. 1989. Inheritance in Chrysanthemum morifolium Ramat. Heredity, 62, 419-423.

LEE, Y. N. 1967. Chromosome numbers of flowering plants in Korea. J. Kor. Cult. Res. Inst., 11, 455-478.

LEE, Y. N. 1975. Taxonomic study on white flowered wild chrysanthemum in Asia. J. Korean Res. Inst. Better Living, 14, 63-79.

LOVELESS, M. D. AND HAMRICK, J. L. 1984. Ecological determinants of genetic structure in plant populations. Ann. Rev. Evol. Syst., 15, 65-95.

MARTIN, G. B., WILLIAMS, J. G. K. AND TANKSLEY, S. D. 1991. Rapid identification of markers linked to a Pseudomonas resistance gene in tomato by using random primers and nearisogenic lines. Proc. Natl. Acad. Sci., U.S.A., 88, 2336-2340.

MICHELMORE, R. W., PARAN, I. AND KESSELI, R. V. 1991. Identification of markers linked to disease-resistance genes by bulked segregant analysis: A rapid method to detect markers in specific genomic regions by using segregating populations. Proc. Natl. Acad. Sci., U.S.A., 88, 9828-9832.

NYBOM, H. AND HALL, H. K. 1991. Minisatellite DNA 'fingerprints' can distinguish Rubus cultivars and estimate their degree of relatedness. Euphytica, 53, 107-114.

QUIROS, C. F., HU, J., THIS, P., CHEVRE, A. M. AND DELSENY, M. 1991. Development and chromosomal localization of genomespecific markers by polymerase chain reaction in Brassica. Theor. Appl. Genet., 82, 627-632.

REITER, R. S., WILliaMS, J. G. K., FELDMANN, K. A., RAFALSKI, J. A., TINGEY, S. V. AND SCOLNIK, P. A. 1992. Global and local genome mapping in Arabidopsis thaliana by using recombinant inbred lines and random amplified polymorphic DNAs. Proc. Natl. Acad. Sci., U.S.A., 89, 1477-1481.

RONALD, W. G. AND ASCHER, P. D. 1975. Self compatibility in garden Chrysanthemum: occurrence, inheritance and breeding potential. Theor. Appl. Genet., 46, 45-54.

SAGHAI-MAROOF, M. A., SOLIMAN, K. M., JORGENSEN, R. A. AND ALLARD, R. w. 1984. Ribosomal DNA spacer-length polymorphisms in barley: Mendelian inheritance, chromosomal location, and population dynamics. Proc. Natl. Acad. Sci., U.S.A., 81, 8014-8018.

SAMBROOK, J., FRITSCH, E. F. AND MANIATIS, T. 1989. Molecular
Cloning: a Laboratory Manual, 2nd edition. Cold Spring Harbour Laboratory Press, New York.

SHImotomaI, N. 1932. Eigenartige Vermehrung der chromosomenzahl bei den Artenbastarden von Chrysanthemum. Bot. Mag. (Tokyo), 46, 789-799.

STEPHENS, L. C., ASCHER, P. D. AND WIDMER, R. E. 1984. Interaction among sporophytic $S$ loci in self-incompatible garden chrysanthemums. Euphytica, 33, 623-631.

SWOFFORD, D. L. AND OLSEN, G. J. 1990. Phylogeny reconstruction. In: Hillis, D. M. and Moritz, C. (eds) Molecular Systematics, Sinauer Ass. pp. 411-501.

TEYNOR, T. M., ASCHER, P. D., WIDMER, R. E. AND LUBY, J. J. 1989. Inheritance of flower color in Dendranthema grandiflora Tzvelev. (Chrysanthemum morifolium Ramat.) using cultivars and inbreds II. Vacuole pigmentation. Euphytica, 42, 297-305.

VAN HEUSDEN, A. W. AND BaChMANN, K. 1992. Genotype relationships in Microseris elegans (Asteraceae, Lactuceae) revealed by DNA amplification from arbitrary primers (RAPDs). Pl. Syst. Evol., 179, 221-233.

WATANABE, K. 1977. The control of diploid-like meiosis in polyploid taxa of Chrysanthemum (Compositae). Jap. J. Genetics, 52, 125-131.

WEINING, S. AND LANGRIDGE, P. 1991. Identification and mapping of polymorphisms in cereals based on the polymerase chain reaction. Theor. Appl. Genet., 82, 209-216.

WELSH, J. AND MCCLELLAND, M. 1990. Fingerprinting genomes using PCR with arbitrary primers. Nucl. Acids. Res., 18, 7213-7218.

WELSH, J., HONEYCUTT, R. J., MCCLELLAND, M. AND SOBRAL, B. W. S. 1991. Parentage determination in maize hybrids using the arbitrarily primed polymerase chain reaction (AP-PCR). Theor. Appl. Genet., 82, 473-476.

WILLIAMS, J. G. K., KUBELIK, A. R., LIVAK, K, J., RAFALSKI, J. A. AND TINGEY, S. V. 1990. DNA polymorphisms amplified by arbitrary primers are useful as genetic markers. Nucl. Acids. Res., 18, 6531-6535.

WOLFF, K. 1991. Analysis of allozyme variability in three Plantago species and a comparison to morphological variability. Theor. Appl. Genet., 81, 119-126.

WOLFF, K., SCHOEN, E. D. AND PETERS-VAN RIJN, J. 1993. Optimizing the generation of Random Amplified Polymorphic DNAs in chrysanthemum (Dendranthema grandiflora Tzvelev.). Theor. Appl. Genet., in press.

WU, K. K., BURNQUIST, W., SORRELLS, M. E., TEW, T. L., MOORE, P. H. AND TANKSLEY, S. D. 1992. The detection and estimation of linkage in polyploids using single-dose restriction fragments. Theor. Appl. Genet., 83, 294-300.

ZAGORSKI, J. S., ASCHER, P. D. AND WIDMER, R. E. 1983. Multigenic self incompatibility in hexaploid Chrysanthemum. Euphytica, 32, 1-7. 